\title{
JURISPRUDENCIA AMBIENTAL EN CASTILLA Y LEÓN (PRIMER SEMESTRE 2018)
}

\author{
IÑIGO SANZ RUBIALES \\ Catedrático de Derecho Administrativo \\ Universidad de Valladolid
}


Sumario: 1. Introducción. 2. Sobre la constitucionalidad del impuesto sobre la eliminación de residuos en vertederos. 3. El mito de Sísifo y el Consejo de Medio Ambiente. 4. La legitimación de las organizaciones ambientales: una interpretación extensiva. 5. La anulación del plan de gestión del lobo. La importancia de los informes en la tramitación. 6. Más sobre el lobo: la anulación del plan cinegético en la submeseta norte.

\section{INTRODUCCIÓN}

La actividad judicial de este segundo semestre no ha sido especialmente abundante, aunque sí que ha tenido una relevancia mediática fuera de lo común, porque algunas de las resoluciones tocan aspectos de gran preocupación social. Destaca, sin duda, el problema del lobo, de su plan de gestión y de la posibilidad o no de cazarlo al norte del Duero.

\section{SOBRE LA CONSTITUCIONALIDAD DEL IMPUESTO SOBRE LA ELIMINACIÓN DE RESIDUOS EN VERTEDEROS}

La sentencia de 22 de diciembre de 2017 resuelve un recurso en el que se solicitaba la devolución de ingresos indebidos derivados del pago del Impuesto sobre la Eliminación de Residuos en Vertederos correspondiente al ejercicio 2012. El demandante, una sociedad mercantil, pedía también el planteamiento de la cuestión prejudicial ante el Tribunal de Justicia de la Unión Europea para que se pronunciase si el citado Impuesto sobre eliminación de residuos en vertederos lesionaba la Directiva 2008/98//CE, "Residuos" al aumentar las diferencias entre las diversas regiones, al gravar únicamente a las entidades establecidas en Castilla y León.

Pues bien, esta Directiva se transpuso al ordenamiento español mediante la Ley 22/2011, de 28 de julio, de Residuos; ley que, además, reconoce de forma expresa en su art. 16.1 que "con estas finalidades [de mejora del medio ambiente] podrán establecerse cánones aplicables al vertido y a la incineración de residuos domésticos".

La Sala acude a una sentencia suya anterior, la sentencia o 1925 de 25 de septiembre de 2014, dictada en el recurso seguido como PO 535/12, que en su FD $5^{\circ}$ da respuesta a las cuestiones que se plantean en el recurso: 
"no es verdad que la Comunidad Autónoma no tenga competencia en la materia (...). El artículo 26.1 de la Ley 1/2012 establece que el Impuesto sobre la eliminación de residuos en vertederos es un tributo propio de la Comunidad de Castilla y León que tiene naturaleza real y finalidad extrafiscal. La finalidad del impuesto es fomentar el reciclado y la valorización de los residuos, así como disminuir los impactos sobre el medio ambiente derivados de su eliminación en vertedero. Consiguientemente, no se grava la recogida de los residuos, ni su tratamiento, sino el daño ambiental derivado de su depósito y por eso el artículo 27 dispone que el hecho imponible es la entrega o depósito de residuos para su eliminación en vertederos situados en el territorio de la Comunidad Autónoma .... Siendo esto así, no hay duda de que el impuesto versa sobre una materia que sí es competencia de la Comunidad Autónoma, como es la protección del medio ambiente (...).

No impide la anterior conclusión el hecho de que los municipios (...) deban prestar el servicio de recogida de residuos $y$, además, en los de más de 5.000 habitantes, el de tratamiento de residuos, por los que pueden establecer la tasa correspondiente (...), toda vez que, como se admite en la demanda, el hecho imponible que se grava con el Impuesto sobre la eliminación de residuos en vertederos es diferente al de la citada tasa".

La licitud de este impuesto se confirma, además, por la doctrina del Constitucional, a la que alude igualmente la Sala, cuando recuerda que, como indica la STC 122/2012, el art. 6.3 LOFCA no impide que las Comunidades Autónomas establezcan tributos propios sobre objetos materiales o fuentes impositivas ya gravadas por los tributos locales, sino que prohíbe, en sus propios términos, "la duplicidad de hechos imponibles, estrictamente, es decir, que la prohibición de doble imposición en él contenida atiende al presupuesto adoptado como hecho imponible y no a la realidad o materia imponible que le sirve de base". 
Por lo tanto, resulta ajustada al ordenamiento la creación de este impuesto de eliminación de residuos en vertederos, compatible con la tasa municipal de recogida de basuras.

\section{EL MITO DE SÍSIFO Y EL CONSEJO DE MEDIO AMBIENTE}

Como se expuso en la crónica correspondiente al primer semestre del año pasado, el Decreto 1/2017, de 12 de enero, por el que se crea y regula el Consejo Regional de Medio Ambiente de Castilla y León vino a re-crear dicho Consejo, cuyo primer decreto regulador, de 2015, había sido anulado en vía contencioso-administrativa por sentencia de la Sala de lo Contencioso del Tribunal Superior de Justicia de 18 de abril de 2016.

Pero las organizaciones ecologistas que impugnaron su creación siguieron cuestionando el contenido del nuevo Decreto, porque la composición del órgano en cuestión no respondía adecuadamente al derecho de participación declarado como objetivo en su Exposición de Motivos. La sentencia de 27 de diciembre de 2017, de la Sala de lo contencioso del Tribunal Superior de Justicia de Castilla y León (Valladolid) anula varios preceptos del Decreto 1/2017 de (re)creación del Consejo. Por una parte, hay, según el FD 5oㅡ, una desproporción entre los representantes de la Administración en el Consejo Regional y los representantes de la sociedad civil (de los 51 miembros con derecho de voto, más de la mitad -33- son cargos de la Administración) y, por otra parte, es escasa la representación de las asociaciones y organizaciones medioambientales en relación al resto de los representantes de otros sectores de la sociedad, cuyos fines son más generales y amplios que los de dichas asociaciones y organizaciones. "Por lo tanto, -concluye el Tribunal en su FD 6ㅇel objetivo del Decreto es reducir el número de órganos de participación y así dotar de mayor racionalidad al sistema de participación de los ciudadanos en materia de medio ambiente. A la vista de tal objetivo, concluimos que lo que no es posible es que, como consecuencia de esta nueva norma (el Decreto 1/2017), los ciudadanos tengan menor participación en la toma de decisiones 
que afectan al medio ambiente". En consecuencia, la Sala anula los artículos $5.1,6.1,7.1$ y 8.1 del Decreto.

Se trata de una decisión judicial de interés, porque no se limita (como podría haber hecho) a constatar la discrecionalidad administrativa en el ejercicio de la potestad autoorganizatoria, sino que compara la Exposición de Motivos con la realidad de la parte dispositiva de la norma y comprueba, así, la distorsión entre la finalidad teórica de la norma (dotar de mas racionalidad a la participación de los ciudadanos en los asuntos ambientales) y la realidad práctica (restricción efectiva de dicha participación).

\section{LA LEGITIMACIÓN DE LAS ORGANIZACIONES AMBIENTALES: UNA INTERPRETACIÓN EXTENSIVA}

La sentencia de 16 de enero de 2018, de la Sala de lo contenciosoadministrativo del TSJ hace referencia a la legitimación de las organizaciones ambientalistas (denominada también "acción popular") reconocida en el art. 23 de la Ley 27/2006 de 18 de julio, por la que se regulan los derechos de acceso a la información, de participación pública y de acceso a la justicia en materia de medio ambiente.

El Juzgado de lo contencioso, resolviendo una demanda de una organización ambiental, condenó a la Administración autonómica a "que reconozca a la actora el carácter de interesada en los procedimientos de ocupación de los montes de utilidad pública identificados en su petición (es decir, los montes de utilidad pública que puedan ser ocupados o, solicitados por los parques eólicos...)". De esta forma, la Administración deberá comunicar los actos administrativos que se dicten, o que se hayan dictado ya, en dichos procedimientos y notificar la resolución que ponga fin al procedimiento.

La Junta entendía que no se le podía reconocer la condición de interesada a la citada asociación sobre la base de dos argumentos: por una parte, el art. 170 del Reglamento de Montes aprobado por Decreto 485/1962, de 22 de febrero, que solo establece que debe darse audiencia a los eventuales beneficiarios de 
la ocupación o servidumbre y a la entidad titular del monte en el expediente administrativo correspondiente; por otra, la ley de Montes, que no contempla la información pública en estos expedientes.

Sin embargo, la sentencia afirma que estas alegaciones "no son de recibo". "No se trata", dice, "de que se haya omitido un trámite de audiencia al interesado que esté previsto en el procedimiento de autorización de ocupación de montes de utilidad pública...". Y parte de la Ley administrativa general (en su momento, la 30/1992) para determinar si la asociación es interesada en los procedimientos en cuestión: "La cuestión es si la asociación recurrente es "interesado" a los efectos del apartado c) de ese precepto en el que se dice que se consideran interesados en el procedimiento administrativo: "Aquellos cuyos intereses legítimos, individuales o colectivos, puedan resultar afectados por la resolución y se personen en el procedimiento en tanto no haya recaído resolución definitiva". Añadiendo el apartado 2 del referido precepto que "Las asociaciones y organizaciones representativas de intereses económicos y sociales, serán titulares de intereses legítimos colectivos en los términos que la Ley reconozca".

A continuación, acude al concepto de interesado en materia ambiental, que cuenta con ciertas peculiaridades en la Ley 27/2006. Según dicha Ley, son personas interesadas (art. 2.2.b) "Cualesquiera personas jurídicas sin ánimo de lucro que cumplan los requisitos establecidos en el artículo 23 de esta Ley (...)". Y continúa la Sala diciendo: "La personación en los procedimientos de autorización para la ocupación de montes de utilidad pública con la finalidad de instalar parques eólicos en la medida en que dichas instalaciones inciden en el medio ambiente (...) permite hacer efectivo el acceso a la justicia y a la tutela administrativa que se reconoce a las personas jurídicas sin ánimo de lucro definidas en el art. 23 de la misma ley. No puede sostenerse con rigor que dichas autorizaciones no tienen trascendencia medioambiental cuando en el condicionado de la autorización se incluyen las determinaciones contenidas en la declaración de impacto ambiental efectuada para la autorización de la instalación del parque eólico y se añaden otras que inciden en su conservación, limpieza, etc.". Y concluye, líneas más abajo: "la asociación recurrente tiene 
derecho a que se le informen de aquellos procedimientos que comporten autorizaciones necesarias para llevar a cabo instalaciones, como los parques eólicos (...)".

En definitiva, frente a las interpretaciones restrictivas de la incidencia ambiental de las actividades económicas y, por tanto, de la legitimación de las organizaciones ambientales en la normativa de montes, hay que afirmar la condición de interesadas de las organizaciones ambientales en los procedimientos de autorización para la ocupación de montes de utilidad pública con la finalidad de instalar parques eólicos, porque dichas instalaciones afectan evidentemente al medio ambiente, y todo ello, de acuerdo con las previsiones de la Ley $27 / 2006$.

\section{LA ANULACIÓN DEL PLAN DE GESTIÓN DEL LOBO. LA IMPORTANCIA DE LOS INFORMES EN LA TRAMITACIÓN}

La sentencia de 25 de enero de 2018 de la Sala de lo contenciosoadministrativo del Tribunal Superior de Justicia (Valladolid) anula el Decreto 14/2016, de 19 de mayo, por el que se aprueba el Plan de Conservación y Gestión del Lobo en Castilla y León. En medio de la fuerte polémica que viene acompañando a la protección y gestión de este cánido, esta sentencia cae como un jarro de agua fría sobre la Administración autonómica, que elaboró y a la que corresponde aplicar dicho Plan.

Hay que adelantar que la impugnación del Decreto no se apoya en incumplimientos sustantivos, sino meramente formales (procedimentales). Y la Sala mantiene el criterio ya tradicional de la jurisprudencia contenciosoadministrativa (con cita expresa de la STS de 21 de enero de 1998), que postula que la ausencia de informes preceptivos, aunque no sean vinculantes, provoca la nulidad de pleno derecho de las normas reglamentarias, de acuerdo con el (vigente) art. 47.2 de la Ley 39/2015. 
Los recurrentes -una asociación ambientalista- alegaron, por una parte, que en el expediente de elaboración del Plan no existía informe del Consejo Regional del Medio Ambiente, sino una mera acta de la sesión en que se analizó el Plan (acta que obra a los folios 1162 y siguientes del expediente). La Sala comprueba que este acta cumple la función de informe, porque de hecho recoge las alegaciones realizadas por los diversos representantes al proyecto de Decreto informado (FD $2^{\circ}$ ) y, por lo tanto, desestima la alegación.

Sin embargo, las demás alegaciones si que son reconocidas: por una parte, la relativa a e la carencia del informe del Comité Técnico de Seguimiento del Plan de Conservación, exigido por el art. 2.4 del Decreto 28/2008, derogado por el Decreto de aprobación del Plan impugnado (aunque en el expediente se incluye un acta donde se afirma que existe un dictamen favorable de dicho órgano a la aprobación del Plan). Como señala la resolución judicial "siendo los supuestos fácticos contemplados diferentes a los inicialmente previstos en el reiterado año 2008, en cuanto a la evolución de la población del lobo, ha de emitirse informe respecto a ello en el que se recoja todo lo atinente a dicha evolución de la especie, lo que redundará en una garantía de acierto de las determinaciones que analizando este supuesto fáctico se adopten sobre el particular en el Decreto impugnado". Y esa información corresponde aportarla al órgano especializado de seguimiento del Plan. Además, "no basta con la mera expresión de que existe un dictamen favorable, según se recoge en la reiterada acta, sino que es necesario que en ella se exprese el parecer de los miembros que componen el Comité sobre el contenido de la norma" (FD $4^{\circ}$ ), porque el art. 76 de la Ley de las Cortes de Castilla y León 3/2001, de 3 de julio, del Gobierno y de la Administración exige en su apartado 3 que los anteproyectos vayan "acompañados de los informes y estudios sobre su necesidad y oportunidad", algo que el acta en cuestión no recoge.

La sentencia va mas lejos, y hace una auténtica teoría general de los informes, ciertamente valiosa, cuando aporta cuatro motivos justificadores de la necesidad y conveniencia de los dictámenes, ante la ausencia de un auténtico informe del citado Comité Técnico en el expediente: “a) Los razonamientos del informe omitido debieran servir de elemento en el que apoyar su decisión el 
órgano con competencia para la resolución final, debiendo entenderse que justifican la oportunidad y acierto de la decisión adoptada, de tal manera que son la base de la motivación de dicha resolución, aunque el órgano que adopta la competencia decisoria pueda apartarse del contenido de dicho informe. b) $\mathrm{Ha}$ de considerarse que el informe, omitido en su contenido, es un elemento fundamental en el procedimiento de aprobación, por la propia configuración efectuada por las normas reglamentarias antes citadas, como órgano de asesoramiento en la materia de la Administración activa. c) La existencia del informe es fundamental, para poder fiscalizar el contenido de la norma impugnada, la motivación de las determinaciones contenidas en la misma (...). En tal sentido la ausencia del informe puede ser generadora de indefensión en los destinatarios de la norma, que de esta forma desconocen los motivos o la causa que han presidido la adopción de la decisión, impidiéndose así la fiscalización jurisdiccional de todos los elementos reglados del acto 0 disposición impugnados. d) El informe del Comité no puede convertirse en un mero automatismo formalista de forma que pueda convalidarse su existencia con la mera expresión de que ha sido sometido a consideración de dicho Comité el proyecto del Decreto".

Finalmente, la Sala constata un último motivo de nulidad: la omisión del estudio económico requerido en el art. 75.2.c de la Ley 3/2001, de 3 de julio, del Gobierno a los anteproyectos. "Esta omisión -dice el FD 9-- del referido requisito supone también una causa de nulidad de pleno derecho del Decreto impugnado".

En definitiva, no han sido ilegalidades de fondo, sino meramente procedimentales, las que han provocado nuevamente la nulidad (esta vez, íntegra) del nuevo Plan del Lobo.

\section{MÁS SOBRE EL LOBO: LA ANULACIÓN DEL PLAN CINEGÉTICO EN LA SUBMESETA NORTE}

También está estrechamente vinculada con la especie protegida en cuestión la posterior (por pocos días) sentencia de la misma sala de 12 de febrero de 
2018, que resuelve el recurso interpuesto, también aquí, por una organización ecologista, de defensa del lobo, contra la resolución de 31 de julio de 2015 de la Dirección General del Medio Natural, por la que aprueba el Plan de Aprovechamientos Comarcales del Lobo en los terrenos cinegéticos situados al norte del rio Duero en Castilla y León para la temporada 2015/16.

Interesa hacer una observación en la que incide el órgano sentenciador: en el momento en el que se dicta la sentencia, la Resolución en cuestión impugnada no estaba en vigor, porque había sido sustituida por resolución de 29 de julio de 2016 de la Dirección General de Medio Ambiente Natural relativa al plan de aprovechamientos comarcales del lobo en los terrenos cinegéticos situados al norte del río Duero para las temporadas 2016/2017, 2017/2018 y 2018/2019, que es el actualmente vigente. Sin embargo, la Sala, siguiendo al Tribunal Constitucional, recuerda que para que la decisión judicial de cierre del proceso por pérdida sobrevenida del objeto resulte respetuosa del derecho fundamental a la tutela judicial efectiva, es necesario que la pérdida del interés legítimo sea completa, y afirma que el nuevo plan aprobado puede adolecer de los mismos defectos que el aquí impugnado; de ahí que la Sala decida resolver en cuanto al fondo el recurso.

El motivo, al igual que en la sentencia anterior, no responde a una cuestión sustantiva, sino formal. No son los cupos (si son grandes o pequeños, si se ajustan o no a la situación real del lobo en la submeseta norte o a cada comarca, etc.), sino la propia condición cinegética del canis lupus en la Comunidad Autónoma. En efecto, la sentencia trae a colación otra resolución de la misma Sala, del año anterior (reseñada en esta revista) que anuló, entre otros, los arts. 13 y 14 del Decreto no 32/2015, de 30 de abril, de la Junta de Castilla y León, que declaraban al lobo especie cinegética (art. 13) y especie cazable en función de la orden anual de caza (art. 14).

Pues bien, señala la sentencia de 12 de febrero, "si el lobo no es especie cinegética, según se dice en la repetida sentencia por no constar en el expediente documentación científica que justifique su catalogación como tal, ni cazable, por no ser la orden anual de caza norma con rango suficiente para 
valorar la utilización razonable de las especies ni para establecer su regulación equilibrada desde el punto de vista ecológico, no cabe establecer un plan que regule su aprovechamiento cinegético al carecer de cobertura legal" (FD $\left.1^{\circ}\right)$.

De esta forma, se rechaza la causa de inadmisibilidad fundada en la pérdida sobrevenida del objeto, propuesta por la demandada y se anula así el Plan de Aprovechamientos comarcales de Castilla y León en los terrenos cinegéticos al norte del Duero para la temporada 2015/2016. 